\begin{tabular}{|c|l|}
\hline Title & Consumption Taxation, Social Status and Indeterminacy in Models of Endogenous Growth with Elastic Labor Supply \\
\hline Author(s) & Itaya, Jun-ichi; Kanamori, Naoshige \\
\hline Citation & Discussion Paper, Series A, 199, 1-35 \\
\hline Issue Date & 2008-04 \\
\hline Doc URL & http://hdl.handle.net/2115/32614 \\
\hline Type & bulletin (article) \\
\hline File Information & DPA 199.pdf \\
\hline
\end{tabular}

Instructions for use 
Discussion Paper, Series A, No. 2008-199

Consumption Taxation, Social Status and

Indeterminacy in Models of Endogenous

Growth with Elastic Labor Supply

Jun-ichi ITAYA \& Naoshige KANAMORI

April, 2008

Graduate School of Economics \& Business Administration

Hokkaido University

Kita 9 Nishi 7, Kita-Ku, Sapporo 060-0809, JAPAN 


\title{
Consumption Taxation, Social Status and Indeterminacy in Models of Endogenous Growth with Elastic Labor Supply*
}

\author{
Jun-ichi Itaya $^{\dagger} \quad$ Naoshige Kanamori ${ }^{\ddagger}$
}

April 11, 2008

\begin{abstract}
This paper examines the effects of consumption taxation on longrun growth in an infinity-lived representative agent model of endogenous growth in which the desire for social status induces private agents to care about others' wealth or consumption levels. We also allow for nonseparable preferences in own consumption, labor supply and social status that may cause indeterminacy of equilibrium. This analysis shows that consumption taxation generally raises (reduces) a long-run growth rate when the balanced growth path is indeterminate (determinate) in the models of wealth-induced social status and consumption externalities.

Keywords: Social Status, Endogenous Growth, Consumption Externality, Indeterminacy, Consumption Taxation, Endogenous Labor Supply

JEL classifications: D62, D90, E62, O40, P10.
\end{abstract}

${ }^{*}$ Earlier versions of this paper were presented at Ritusmeikan University, Okayama University, Hokkaido University and the 2008 Spring Meeting of the Japanese Economic Association held at Tohoku University. Our thanks go to Yoichi Gokan, Hiroshi Kurata, Masao Oda, and Naoto Jinji for their helpful comments. The first author acknowledges financial support from the Japan Society for the Promotion of Science, under Grant No. 19530145. Any remaining errors are ours.

${ }^{\dagger}$ Corresponding author: Graduate School of Economics and Business Admministration, Hokkaido University, Sapporo, 060-0809, Japan. Tel:+81-11-706-2858; Fax:+81-11-7064947; E-mail: itaya@econ.hokudai.ac.jp

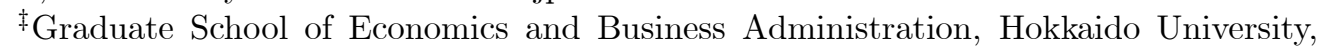
Sapporo, 060-0809, Japan. E-mail; nao-k@pop.econ.hokudai.ac.jp 


\section{Introduction}

The effect of consumption taxation on an economy has been debated for a long time. The supporting argument for consumption taxation claims that a proportional consumption tax, which is constant through time, does not directly distort intertemporal consumption-savings choice. In the standard neoclassical (exogenous) growth model without labor-leisure choice, Schenone (1975), Summers (1981), Abel and Blanchard (1983), Auerbach and Kotlikoff (1987), and Itaya (1991) establish the well-known neutrality result that a consumption tax affects neither investment, the stock of capital nor consumption during the transition path as well as in the steady state, provided that the tax revenue collected is fully rebated to households. In contrast, Devereux and Love (1994), and Milesi-Ferretti and Roubini (1998) analyze the effects of consumption taxation on economic growth using the Lucas-type, two-sector endogenous growth model in which the growth process is driven by the joint accumulation of physical and human capital. They show that, allowing for a leisure-labor choice, a rise in the consumption tax reduces the economy's long-run growth rate as a consequence of a reduction in labor supply, since the income effect activated by the consumption tax is partly nullified by the redistributed lump-sum transfers. On the other hand, Stokey and Rebelo (1995) show that consumption taxation has no growth effects if the tax revenue is not rebated to households, because the substitution and income effects of the consumption tax on labor supply exactly cancel each other out.

In reality, individuals care about their social status. There are two alternative ways of modeling the inclusion of social status concern into models of economic growth. In the existing literature, social status concern has been modeled as the inclusion of others' wealth or consumption levels in the preferences of households. Kurz (1968), Zou (1994, 1995) and Bakshi and Chen Model I (1996) have analyzed the spirit-of-capitalism (or the absolute wealth) model in which households care only about the absolute level of their own wealth holdings. Those models also appear to be consistent with Weber's view (1958), in that the continual accumulation of wealth is moti- 
vated not only for the sake of future consumption, but also for its own sake. More recently, Bakshi and Chen (1996) in their Model II, Corneo and Jeanne (1997), Futagami and Shibata (1998), and Long and Shimomura (2004) have explored a model in which the determinant of social status concern is households' regard for the ratio of one's own wealth to their society's average wealth (referred to as the 'relative wealth' model).

Alternatively, social status concern can be captured by using the ratio of individual own consumption to society's average consumption. This model is called the 'relative consumption' model, which is attributed to Veblen (1899) and Dusenberry (1949). The model has been elaborated by Harbaugh (1996) and Rauscher (1997). Gali (1994), and Fisher and Hof (2000) have developed more general consumption externalities models that include the relative consumption model as a special case. The distinguishing feature of the latter models is that consumption externalities caused by others' consumption may either reduce or enhance the felicity of own consumption or its marginal utility on the grounds that individuals may display either jealously or altruism toward other people's consumption. ${ }^{1}$

The wealth-enhanced social status and consumption externalities models in the above-mentioned literature treat labor supply as inelastic. Weder (2000) and Alonso-Carrera et al. (2005) are exceptions. Weder shows that, in a two-sector growth model, consumption externalities reduce the strength of increasing return needed to generate indeterminacy. In contrast, AlonsoCarrera et al. show that, even in a one-sector growth model, indeterminacy may arise when the elasticity of the labor demand curve is larger than the elasticity of the Frisch labor supply curve in addition to nonseparable preferences in own consumption, average consumption and leisure. Their papers consider how the presence of consumption externalities influences the likelihood of indeterminacy of equilibria arising in exogenous and/or endogenous growth models with elastic labor supply.

\footnotetext{
${ }^{1}$ One common finding of these studies is that the long-run growth rate of the economy increases with the strength of social status concern. More precisely, the stronger this concern, the higher the marginal private return to accumulation, and, hence, the greater the economy's growth rate. Although status-seeking is a rat race for private individuals, it promotes long-run growth by strengthening an incentive to save.
} 
Recently, Chang (2006) investigated the relationship between consumption taxation and economic growth in the relative wealth model. He showed that a rise in the consumption tax rate leads to a larger stationary capital stock in an exogenous growth model, while its rise stimulates the long-term growth rate in an endogenous growth model; in short, the neutrality of consumption taxation is not tenable in the long run at both the level sense and the growth rate sense, and the optimal consumption tax policy should subsidize consumption. Nevertheless, since he assumes not only inelastic labor supply, but also that the instantaneous utility function is additively separable in consumption and relative wealth, these critical assumptions would limit the validity of his results. The next most natural research agenda, therefore, is to investigate the effects of consumption taxation on economic growth in a status preferences model that allows for endogenous labor supply. More importantly, as long as labor supply is fixed, the consumption tax acts as nondistortionary lump-sum taxes, whereas endogenizing labor supply converts the nondistorting consumption tax to distortionary taxes. The assumption of fixed labor supply would lead us to overestimate the superiority of consumption taxation over other distortionary taxes advocated by the proponents of this tax. Indeed, Chang (2006, p125) suggests such an extension as an open question by saying that, "Obviously, further investigation into our analysis on the basis of endogenous leisure-labor desecration is the next step".

The purposes of this paper are not only to tackle this open question, but also to investigate how the interaction between status preferences and labor supply affects growth effects as well as welfare effects of consumption taxation. We are particularly interested in how the effects of consumption taxation on long-run growth are affected by the stability properties of the growth model with status preferences as well as with endogenous labor supply. We use Romer's (1986) learning-by-doing, one-sector model of endogenous growth augmented with endogenous labor supply and with nonseparable preferences in consumption, social status and leisure. According to Bennett and Farmer (2000), the inclusion of endogenous labor supply in the nonseparable utility function makes indeterminacy of equilibria possible. Specifically, 
unlike Weder (2000) and Alonso-Carrera et al. (2005), we assume the CRRA form for an instantaneous utility function to model such preferences, which enables us to study a wider class of status preferences models by varying only the parameter values that represent the strength of social status concern and/or the degree of externalities generated by others' wealth holdings or others' consumption. In addition to the virtue of tractability, it would provide more general implications of consumption tax policy as well as the model's dynamics as compared to the case of separability utility coupled with fixed labor supply (e.g., Rauscher 1997; Corneo and Jeanne 1997; Futagami and Shibata 1998; Long and Shimomura 2004; Chang 2006).

Section 2 presents a model of endogenous growth with elastic labor supply in which individuals care about the absolute level of wealth (i.e., a stock of capital) they own as well as society's average wealth. This model encompasses special cases of the capitalistic spirit and relative wealth models. Section 3 derives the conditions under which a balanced growth path is indeterminate. Section 4 investigates the effects of consumption taxation on growth as well as on social welfare. We find that consumption taxation raises (reduces) the long-run growth rate when the balanced growth path is indeterminate (determinate), provided the desire for social status is not too strong. In other words, the long-run growth rate could be lowered in response to higher rates of consumption taxation, contrary to the finding of Chang (2006). Section 5 analyzes the consumption externalities model in which individuals care about other people's consumption as well as their own. In Section 6 we find that consumption taxation raises (reduces) a long-run growth rate if and only if the balanced growth path is indeterminate (determinate), provided that the Frisch labor supply and labor demand curves cross with the 'wrong' slopes, otherwise vice versa. Section 7 concludes the paper. Some mathematical derivations will be given in the appendices. 


\section{The model}

\subsection{Firms}

There is a continuum of identical and competitive firms in the economy, with the total number normalized to one. The representative firm $i$ produces output using a constant returns-to-scale, Cobb-Douglas technology:

$$
y=k_{i}^{a} l_{i}^{b} X, a+b=1
$$

where $k_{i}$ and $l_{i}$ are the capital stock and labor hours employed by firm $i$, respectively. The term $X$ represents productive externalities resulting from learning-by-doing in production or investment that are taken as given by each firm. Following Benhabib and Farmer (1994), we further specify these externalities as:

$$
X=k^{\alpha-a} l^{\beta-b}, a<\alpha \leq 1, b<\beta<1, \alpha+\beta>1,
$$

where $k$ and $l$ represent the aggregate (= average) stock of capital and aggregate (= average) labor hours, respectively. In a symmetric equilibrium, all firms take the same action such that for all $i, y_{i}=y, k_{i}=k$ and $l_{i}=l$. Substituting (2) into (1), we obtain the following social production technology:

$$
y=k^{\alpha} l^{\beta}
$$

We first assume that capital externalities are strong enough to generate sustained endogenous growth; that is, $\alpha=1$.

The competitive factor payments are:

$$
\begin{gathered}
r=a(y / k)=a l^{\beta}, \\
w=b(y / l)=b k l^{\beta-1},
\end{gathered}
$$

where $r$ and $w$ denote the return to capital and the real wage rate, respec- 
tively.

\subsection{Households care about absolute or relative wealth}

There is a unit measure of identical infinitely lived households, $i$, each of which maximizes its lifetime utility:

$$
\int_{0}^{\infty} U\left(c_{i}, l_{i}, k_{i}, k\right) e^{-\rho t} d t \equiv \int_{0}^{\infty} \frac{\left[c_{i}\left(1-l_{i}\right)^{\eta}\left(k_{i} / k^{\theta}\right)^{\gamma}\right]^{1-\sigma}-1}{1-\sigma} e^{-\rho t} d t
$$

where $c_{i}, 0 \leq l_{i} \leq 1, k_{i}$ and $k$ are household $i$ 's consumption, household $i$ 's hours worked, the stock of capital held by household $i$ and society's average capital stock, respectively. The positive parameters $\eta$ and $\gamma$ respectively denote the weights on utility toward leisure and the holdings of capital stock, the latter of which measures the desire for social status or the intensity of the spirit of capitalism, while the positive parameters $\sigma$ and $\rho$, respectively, denote the inverse of the intertemporal elasticity of substitution in consumption and the subjective rate of time preference. The instantaneous utility function $U($.$) in (6) is seen to be increasing in c_{i}$ and $k_{i}$, while decreasing in $l_{i}$ and $k$. Moreover, we assume that the utility function is concave in $c_{i}$, $1-l_{i}$, and $k_{i}$, which implies that $\sigma>\eta /(1+\eta) .^{2}$

The parameter $\theta \in[0,1]$ indexes the importance of an individual's wealth relative to society's average wealth. When $\theta=0$, the model corresponds to the spirit-of-capitalism model as in Kurz (1986), Zou (1994, 1995), whereas when $\theta=1$, the model corresponds to the relative wealth model as in Cole et al. (1992), Bakshi and Chen's Model II (1996), Corneo and Jeanne (1997),

\footnotetext{
${ }^{2}$ Alternatively, one could use the following slightly more general utility function rather than that in the form in (6):

$$
\int_{0}^{\infty} \frac{\left[c_{i} V\left(l_{i}\right)\left(k_{i} / k^{\theta}\right)^{\gamma}\right]^{1-\sigma}-1}{1-\sigma} e^{-\rho t} d t
$$

where $V\left(l_{i}\right) \in C^{2}, V^{\prime}\left(l_{i}\right)<0$ and $V^{\infty}\left(l_{i}\right)>0$. As noted by King et al. (1988), this instantaneous utility function without social status concern is the most general one compatible with balanced growth and a stationary labor supply. However, because the analysis based on this utility function will be complicated in terms of notation without adding any further insights, we do not adopt this utility function.
} 
and Futagami and Shibata (1998).

The budget constraint faced by the representative household $i$ is given by:

$$
\dot{k}_{i}=w l_{i}+(r-\delta) k_{i}-\left(1+\tau_{c}\right) c_{i}+z_{i}, \quad k_{i}(0)=k_{i 0} \text { given, }
$$

where $\delta$ and $z_{i}$ stand for the depreciation rate and transfer payments that are fully rebated to households in a lump sum fashion, respectively. The variable $\tau_{c}$ indicates a proportional tax rate, which is constant through time, applied to consumption.

Taking into account the fact that each household is small enough to neglect its own wealth holdings compared to the average wealth in the economy, we obtain the following first-order conditions:

$$
\begin{gathered}
\frac{\left[c_{i}\left(1-l_{i}\right)^{\eta}\left(k_{i} / k^{\theta}\right)^{\gamma}\right]^{1-\sigma}}{c_{i}}=\left(1+\tau_{c}\right) \lambda_{i}, \\
\frac{\eta}{1-l_{i}}\left[c_{i}\left(1-l_{i}\right)^{\eta}\left(\frac{k_{i}}{k^{\theta}}\right)^{\gamma}\right]^{1-\sigma}=\lambda_{i} w, \\
\frac{\dot{\lambda}_{i}}{\lambda_{i}}=\rho+\delta-\left[r+\gamma \frac{c_{i}}{k_{i}}\left(1+\tau_{c}\right)\right],
\end{gathered}
$$

together with the given initial level of capital stock $k_{i 0}$ held by household $i$ and the transversality condition $\lim _{t \rightarrow \infty} e^{-\rho t} \lambda_{i}(t) k_{i}(t)=0$, where $\lambda_{i}$ represents the shadow price of household $i$ 's capital holdings. Eq.(10) is the Euler equation determining the optimal accumulation of capital according to the difference between the net effective rate of return on capital, $r+\gamma\left(c_{i} / k_{i}\right)(1+$ $\left.\tau_{c}\right)-\delta$, and the rate of time preference, $\rho$. The effective rate of return on capital consists of the marginal utility of relative wealth plus the marginal product of capital. ${ }^{3}$ Dividing (9) by (8) and taking into account (5) results in:

\footnotetext{
${ }^{3}$ More precisely, the term $\gamma\left(c_{i} / k_{i}\right)$ on the right-hand side of (10) stands for household $i$ 's marginal rate of substitution (MRS) between own consumption and relative wealth; that is:

$$
M R S_{i} \equiv \frac{\partial U / \partial\left(k_{i} / k\right)}{\partial U / \partial c_{i}}=\gamma \frac{c_{i}}{k_{i}} .
$$
}




$$
\frac{\eta}{1-l_{i}} c_{i}=\frac{w}{1+\tau_{c}}=\frac{b k l^{\beta-1}}{1+\tau_{c}} .
$$

This condition requires that household $i$ 's marginal rate of substitution $(M R S)$ between leisure and own consumption should be equated to the real wage rate, adjusted for the consumption tax at each point in time. A higher consumption tax rate induces substitution away from consumption toward leisure through raising the after-tax price of consumption, thereby reducing labor supply for a given level of the wage rate. The government is assumed to balance its budget in accordance with $z=\tau_{c} c$, abstracting from government spending, where $c$ represents society's average consumption.

\section{Indeterminacy}

In this section, we examine the conditions under which local indeterminacy occurs in the market economy described in the previous section.

Imposing symmetry (i.e., $c=c_{i}$ for $i \in[0,1]$ and so on), taking logs and the time derivative of (8) yields:

$$
(1-\sigma)\left[\frac{\dot{c}}{c}-\eta \frac{\dot{l}}{1-l}+\gamma(1-\theta) \frac{\dot{k}}{k}\right]-\frac{\dot{c}}{c}=\frac{\dot{\lambda}}{\lambda}
$$

Further, substituting (10), together with (4), into the above expression results in:

$$
-\sigma \frac{\dot{c}}{c}-(1-\sigma) \eta \frac{\dot{l}}{1-l}+(1-\sigma) \gamma(1-\theta) \frac{\dot{k}}{k}=\rho+\delta-\left[a l^{\beta}+\gamma\left(1+\tau_{c}\right) \frac{c}{k}\right] .
$$

On the other hand, taking logs and the time derivative of the $M R S$ condition (11) yields:

$$
\frac{\dot{c}}{c}-\frac{\dot{k}}{k}=\left[-\frac{l}{1-l}+\beta-1\right] \frac{\dot{l}}{l} .
$$

Substituting (13) and the goods market equilibrium condition: 


$$
\frac{\dot{k}}{k}=l^{\beta}-\frac{c}{k}-\delta,
$$

into (12), together with (11), and rearranging, we finally obtain:

$$
\frac{i}{l}=\frac{N(l)}{\triangle(l)}
$$

where

$$
\begin{aligned}
N(l) \equiv & \rho-\left(a l^{\beta}-\delta\right)-\gamma \frac{b}{\eta}(1-l) l^{\beta-1} \\
& +[\sigma-(1-\sigma) \gamma(1-\theta)]\left[l^{\beta}-\frac{b}{\eta} \frac{(1-l) l^{\beta-1}}{1+\tau_{c}}-\delta\right],
\end{aligned}
$$

and $\Delta(l) \equiv[\sigma-(1-\sigma) \eta][l /(1-l)]+\sigma(1-\beta)>0$.

The positive sign of $\Delta(l)$ follows from the facts that $\sigma-(1-\sigma) \eta>0$, which is implied by the concavity of the utility function, and that $1-\beta>0$. The BGE path is characterized by a situation where both $c$ and $k$ grow at the same rate (denoted by $\hat{g}$ ), while leaving $l$ constant (hence, $\dot{l}=0$ ). ${ }^{4}$ As a result, the BGE level of employment, denoted by $\hat{l}$, is obtained by setting $N(\hat{l})=0$ :

$$
\frac{a \hat{l}^{\beta}+\gamma(b / \eta)(1-\hat{l}) \hat{l}^{\beta-1}-(\rho+\delta)}{\sigma-(1-\sigma) \gamma(1-\theta)}=\hat{l}^{\beta}-\frac{b}{\eta} \frac{(1-\hat{l}) \hat{l}^{\beta-1}}{1+\tau_{c}}-\delta .
$$

Since our principal focus lies on the BGE path that features positive growth, we assume that the economy exhibits sustained growth (i.e., $a \hat{l}^{\beta}+\gamma(b / \eta)(1-$ $\left.\hat{l}) \hat{l}^{\beta-1}-(\rho+\delta)>0\right)$, thus leading to the positivity of the denominator of the left-hand side of $(16)$ (i.e., $\sigma-(1-\sigma) \gamma(1-\theta)>0)$. We impose this restriction from now on. The presence of status preferences (i.e., $\gamma \neq 0$ ) affects a

\footnotetext{
${ }^{4}$ Making use of (8) and the fact that $\hat{k}=k_{0} e^{\hat{g} t}$ and $\hat{c}=c_{0} e^{\hat{g} t}$ along the BGE, the transversality condition associated with the BGE becomes:

$\lim _{t \rightarrow \infty} \hat{k} \hat{\lambda} e^{-\rho t}=\left(1+\tau_{c}\right)^{-1} c_{0}{ }^{-\sigma}(1-\hat{l})^{\eta(1-\sigma)} k_{0}{ }^{1+(1-\theta) \gamma(1-\sigma)} \lim _{t \rightarrow \infty} \exp [\hat{g}\{1+(1-\theta) \gamma\}(1-\sigma)-\rho] t=0$,

where $\hat{g}$ stands for a growth rate along the BGE and $c_{0}$ is the initial level of consumption that is endogenously determined so as to satisfy (11), given $k_{0}$ and $\hat{l}$. This transversality condition is met if $\rho>g\{1+(1-\theta) \gamma\}(1-\sigma)$.
} 
long-run growth rate through two channels: modifying the magnitude of the intertemporal substitution in consumption, $[\sigma-(1-\sigma) \gamma(1-\theta)]^{-1}$, and augmenting the rate of return on capital, $a \hat{l}^{\beta}$, by the term $\gamma(b / \eta)(1-\hat{l}) \hat{l}^{\beta-1}$, which reflects the fact that the preferences for wealth-enhanced social status form an engine of growth.

Because $i$ in (15) depends only on $l$, not on $k$, in order to know the stability properties of the BGE, we only have to identify the sign of $d \dot{l} / d l$ evaluated at $\hat{l}$. Differentiating (15) with respect to $l$ yields:

$$
\left.\frac{d(\dot{l} / l)}{d l}\right|_{l=\hat{l}}=\frac{N^{\prime}(\hat{l}) \Delta(\hat{l})-N(\hat{l}) \Delta^{\prime}(\hat{l})}{\{\Delta(\hat{l})\}^{2}}=\frac{N^{\prime}(\hat{l})}{\Delta(\hat{l})}
$$

where $N(\hat{l})=0$ and

$$
\begin{gathered}
N^{\prime}(\hat{l}) \equiv[\sigma-(1-\sigma) \gamma(1-\theta)] \\
\times\left[-\frac{a \beta-\gamma(b / \eta)\left\{1+(1-\hat{l})(1-\beta) \hat{l}^{-1}\right\}}{\sigma-(1-\sigma) \gamma(1-\theta)} \hat{l}^{\beta-1}\right. \\
\left.+\beta \hat{l}^{\beta-1}+\frac{b}{\eta} \frac{\left\{1+(1-\hat{l})(1-\beta) \hat{l}^{-1}\right\}}{1+\tau_{c}} \hat{l}^{\beta-1}\right] \mathrm{R} 0 .
\end{gathered}
$$

The sign of $N^{\prime}(\hat{l})$ in $(18)$ is in general undetermined, as is the sign of $d \dot{l} / d l$ despite $\Delta(\hat{l})>0$. If $N^{\prime}(\hat{l})$ is positive, then $d \dot{l} / d l>0$, and thus the fixed point $\hat{l}$ is a repeller; consequently, the BGE is locally determinate. In contrast, if $N^{\prime}(\hat{l})$ is negative, then $d l / d l<0$, and thus the fixed point $\hat{l}$ is an attractor; hence, the BGE is locally indeterminate.

In Figs.1-3 the graph of (16) is drawn, where the curves corresponding to the left-hand side of (16) (denoted by $\dot{c} /\left.c\right|_{l=\hat{l}}$ ) may be upward sloping or downward sloping, while its right-hand side (denoted by $k /\left.k\right|_{l=\hat{l}}$ ) is always upward sloping (see Appendix A). ${ }^{5}$ The intersection of these two curves gives us the common growth rate of consumption and capital, $\hat{g}$, on the vertical axis, and the BGE level of labor supply, $\hat{l}$, on the horizontal axis. $N^{\prime}(\hat{l})<$ 0 graphically implies that at the fixed point $\hat{l}$, the curve $\dot{k} /\left.k\right|_{l=\hat{l}}$ cuts the

\footnotetext{
${ }^{5}$ Since $N^{\prime}(\hat{l})<0$ in $(18)$ implies $a \beta-\gamma(b / \eta)\left\{1+(1-\hat{l})(1-\beta) \hat{l}^{-1}\right\}>0$, it follows from (A3) that the curve $\dot{c} /\left.c\right|_{l=\hat{l}}$ is always positively sloped when the BGE is indeterminate.
} 


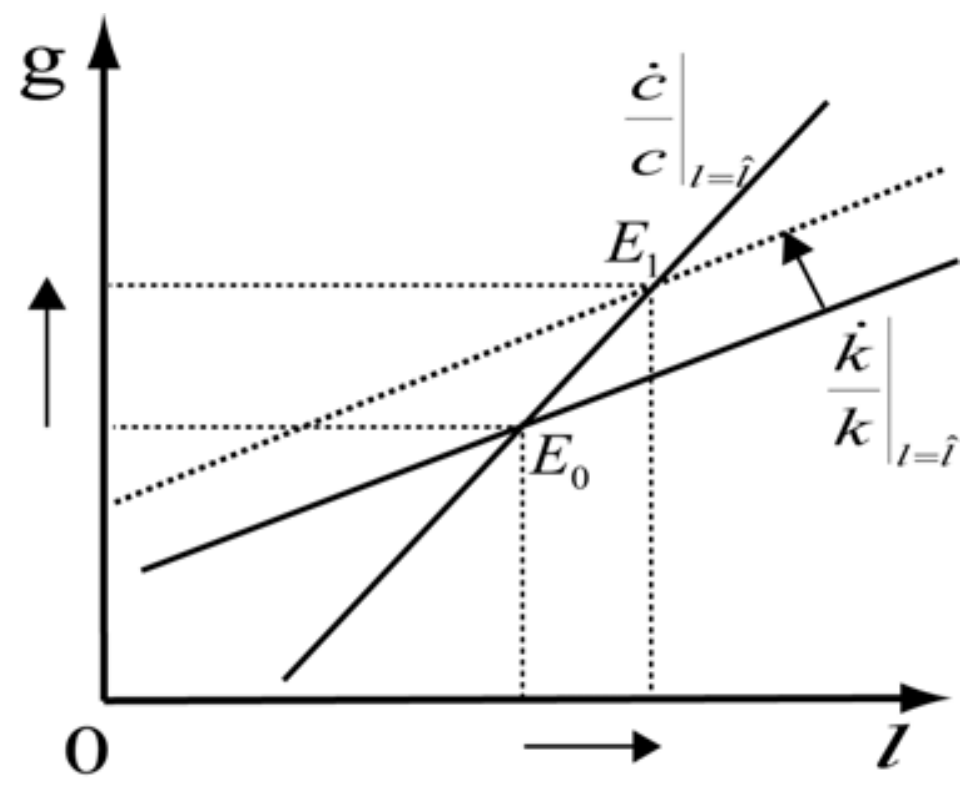

Figure 1: The effect of an increase in the consumption tax on the growth rate $\hat{g}$, either if $N^{\prime}(\hat{l})<0$ in the relative wealth model or if $M^{\prime}(\hat{l})<0$ in the consumption externalities model.

$\dot{c} /\left.c\right|_{l=\hat{l}}$ curve from above as illustrated in Fig.1, whereas $N^{\prime}(\hat{l})>0$ implies the opposite, as illustrated in Figs. 2 and 3 depending on the upward and downward sloping of the $\dot{c} /\left.c\right|_{l=\hat{l}}$ curve [see (A.4) and (A.5) in Appendix A]. Taken together, we have:

Proposition 1 Assume that the utility function is given by (6). Then, a $B G E$ is locally indeterminate (determinate) if and only if $N^{\prime}(\hat{l})<0\left(N^{\prime}(\hat{l})>\right.$ $0)$, where

$$
\begin{aligned}
\operatorname{sign}\left[N^{\prime}(\hat{l})\right] & =\operatorname{sign}[-a \beta+\gamma \Lambda(\hat{l}) \\
& \left.+\{\sigma-(1-\sigma) \gamma(1-\theta)\}\left\{\beta+\frac{\Lambda(\hat{l})}{1+\tau_{c}}\right\}\right]
\end{aligned}
$$

with $\Lambda(\hat{l}) \equiv(b / \eta)\left\{1+(1-\hat{l})(1-\beta) \hat{l}^{-1}\right\}>0$ and $\sigma-(1-\sigma) \gamma(1-\theta)>0$.

This proposition identifies a source for the emergence of an indeterminate BGE, namely, the relative responsiveness of the steady state growth rate 


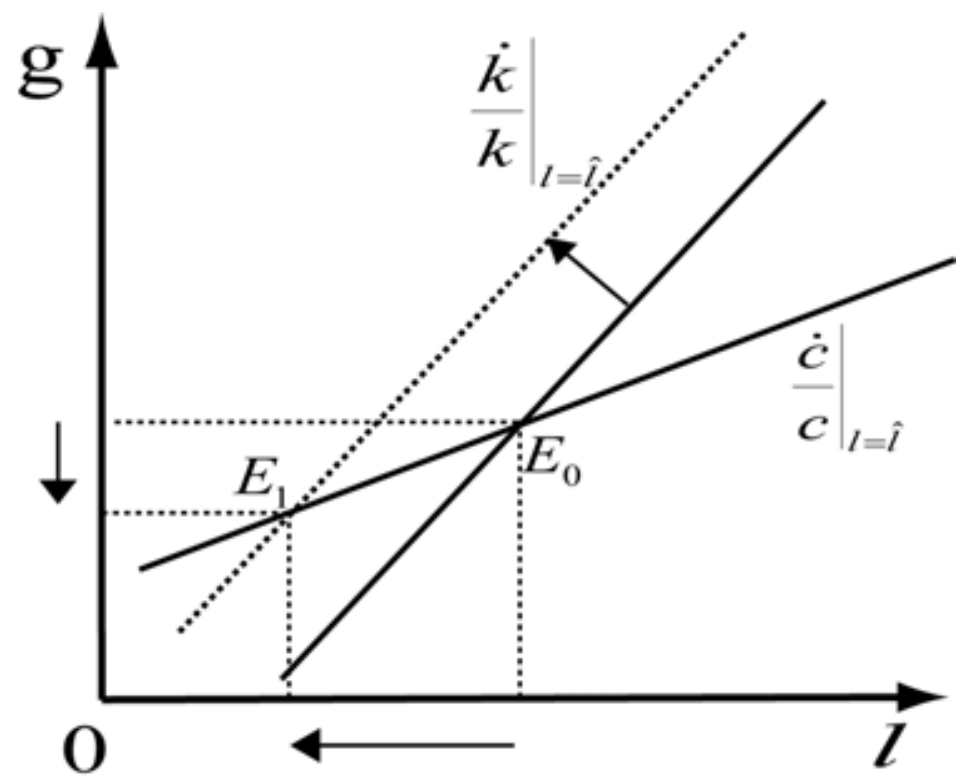

Figure 2: The effect of an increase in the consumption tax on the growth rate $\hat{g}$, either if $N^{\prime}(\hat{l})>0$ and $a \beta-\gamma(b / \eta)\left\{1+(1-\hat{l})(1-\beta) \hat{l}^{-1}\right\}>0$ in the relative wealth model or if $M^{\prime}(\hat{l})>0$ in the consumption externalities model

of consumption given by Appendix $\mathrm{A}$ and the growth rate of capital given by (14) associated with a stationary level of employment, which in turn determines the sign of $N^{\prime}(\hat{l})$.

Further inspection of $N^{\prime}(\hat{l})$ in (18) reveals that $N^{\prime}(\hat{l})>0$ for $\sigma \geq 1$. To put it differently, the elastic elasticity of substitution in consumption (i.e., $\sigma<1$ ) is a necessary condition for indeterminacy, which is consistent with those models without status preferences such as those of Bennett and Farmer (2000), and Pelloni and Waldmann (2000). Moreover, by setting $\gamma=0$ and $\theta=1$ in (18), respectively, we have:

$$
N^{\prime}(\hat{l})=-a \beta+\sigma\left\{\beta+\frac{\Lambda(\hat{l})}{1+\tau_{c}}\right\} \text { for } \gamma=0,
$$

and

$$
N^{\prime}(\hat{l})=-a \beta+\gamma \Lambda(\hat{l})+\sigma\left\{\beta+\frac{\Lambda(\hat{l})}{1+\tau_{c}}\right\} \text { for } \theta=1
$$




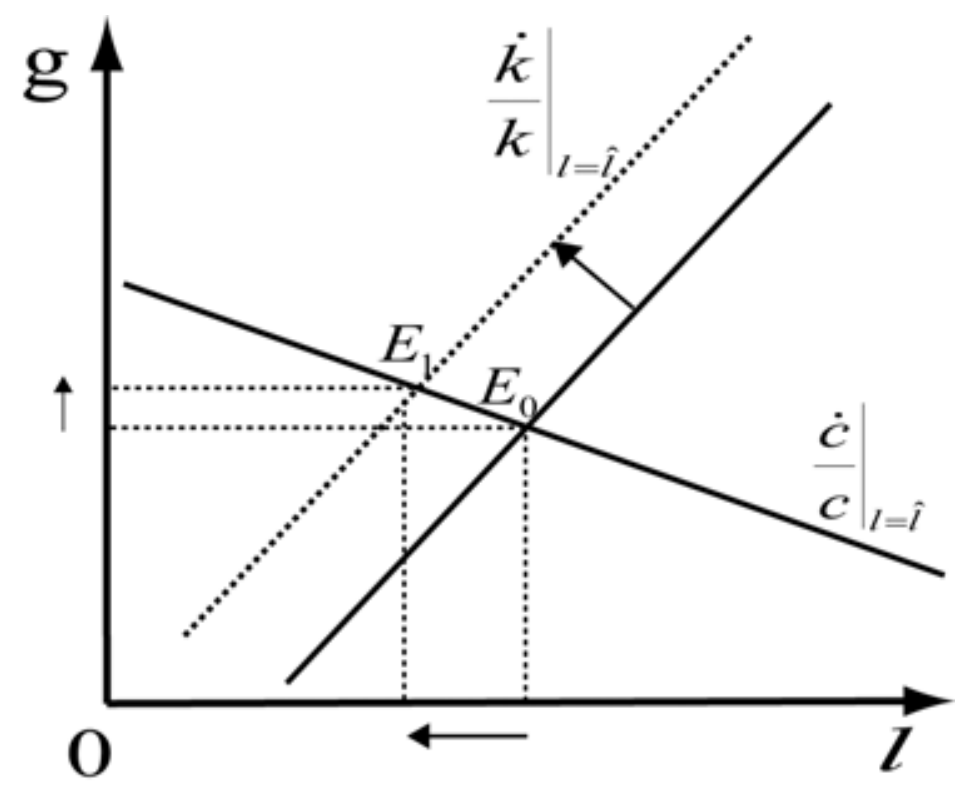

Figure 3: The effect of an increase in the consumption tax on the growth rate $\hat{g}$, if $N^{\prime}(\hat{l})>0$ and $a \beta-\gamma(b / \eta)\left\{1+(1-\hat{l})(1-\beta) \hat{l}^{-1}\right\}<0$ in the relative wealth model.

It is seen that $\sigma<1$ is still a necessary condition for indeterminacy. It is also observed that it is uncertain whether the presence of wealth-enhanced social status preferences (i.e., $\gamma \neq 0$ ) makes indeterminacy of equilibria more or less likely to occur, whereas the stronger the negative externality from the others' capital stock, the less likely it is that indeterminacy will emerge.

To interpret our results, we employ the institution of the capital market and assume that $\sigma<1$. Suppose that the economy is in equilibrium and households decide to increase savings in anticipation of a higher rate of future return on capital. If the increase in savings is an equilibrium decision, then there will be multiple paths, and thus indeterminacy arises. The increased savings causes a reduction in current consumption, which leads to increasing its marginal utility. The increase in savings can be an equilibrium decision only if leisure and/or the holdings of own capital relative to the average capital stock is decreased, which reduces the marginal utility of current consumption [see the left-hand side of (8)]. The stronger the effects on 
the marginal utility of own consumption through these channels, the greater the effective intertemporal substitution elasticity of consumption measured by $[\sigma-(1-\sigma) \gamma(1-\theta)]^{-1}$. In addition, a higher level of employment boosts the rate of return (i.e., $a l^{\beta}$ ), which in turn raises the consumption growth rate defined by (A.3) in Appendix A, but also weakens the desire for social status. ${ }^{6}$ Taken together, when the effective intertemporal substitution elasticity and the elasticity of the return to capital in terms of employment are both sufficiently large, the response of consumption growth rate may become large enough to make indeterminacy possible.

We conduct a numerical analysis in order to examine the empirical plausibility of indeterminacy when $\sigma<1$. We assume that

\begin{tabular}{lcccc}
\hline Variable & $\sigma$ & $\gamma$ & $\theta$ & $\delta$ \\
\hline Calibrated value & 0.85 & 0.02 & 0.01 & 0.1 \\
\hline
\end{tabular}

Table 1

We further assume the following 'empirically stylized facts' for the economy lying on the BGE path:

\begin{tabular}{lccccc}
\hline Variable & $\hat{g}$ & $r-\delta$ & $c / y$ & $\tau_{c}$ & $\hat{l}$ \\
\hline Calibrated value & 0.07 & 0.1 & 0.6 & 0.1 & 0.25 \\
\hline
\end{tabular}

Table 2

Using these calibrated values, we obtain the remaining values and check the sign of $N^{\prime}(\hat{l})$. Combining (11), the government's budget constraint $z=$ $\tau_{c} c,(14)$ and (16) yield the vector of other parameters $\{\beta, z / y, a, b, \eta, \rho\}=$ $\{0.61,0.06,0.47,0.53,2.41,0.046\}$, which delivers $N^{\prime}(\hat{l})=1.03>0$, so that indeterminacy does not occur. To make it possible, we simply replace only

${ }^{6}$ Differentiating (8) with respect to $k$ yields:

$$
\partial U^{2} / \partial c \partial k=(1-\theta) \gamma(1-\sigma) c^{-\sigma}(1-l)^{\eta(1-\sigma)} k^{(1-\theta) \gamma(1-\sigma)-1}>0 \text { if } \sigma<1 .
$$


the values of $\sigma$ and $g$ by $\sigma=0.56$ and $g=0.01$, which gives rise to the vector of $\{\beta, z / y, a, b, \eta, \rho\}=\{0.93,0.06,0.73,0.27,1.24,0.098\}$ and thus $N^{\prime}(\hat{l})=-0.028<0$. Nevertheless, it turns out that, in this case, the share of capital income to GDP, $a$, is larger than that of labor income, $b$. Although we have investigated many combinations of other empirically plausible parameter values, we find that indeterminacy occurs only when $a>b$.

\section{The effects of consumption taxation in the relative wealth model}

In this section, we examine the long-run impacts of consumption taxation along the BGE path of the present model. We study the effects of changes in the consumption tax on employment and thus on the growth rate along the BGE path. Totally differentiating (16) with respect to the consumption tax, $\tau_{c}$, and manipulating yields:

$$
\frac{d \hat{l}}{d \tau_{c}}=-[\sigma-(1-\sigma) \gamma(1-\theta)] \frac{b}{\eta} \frac{(1-\hat{l}) \hat{l}^{\beta-1}}{\left(1+\tau_{c}\right)^{2}}\left[N^{\prime}(\hat{l})\right]^{-1} .
$$

It follows that since $\sigma-(1-\sigma) \gamma(1-\theta)>0$, the effect of the consumption tax on the BGE level of employment depends solely on the sign of $N^{\prime}(\hat{l})$; that is, on whether the BGE displays local determinacy or indeterminacy. In other words, an increase in the consumption tax raises (reduces) employment if and only if the BGE path displays local indeterminacy (determinacy).

After substituting (11) for $c / k$ in (14), we differentiate the resultant expression with respect to $\tau_{c}$ to yield:

$$
\frac{d \hat{g}}{d \tau_{c}}=\frac{a \beta-\gamma(b / \eta)\left\{1+(1-\hat{l})(1-\beta) \hat{l}^{-1}\right\}}{\sigma-(1-\sigma) \gamma(1-\theta)} \hat{l}^{\beta-1} \frac{d \hat{l}}{d \tau_{c}},
$$

where $\hat{g} \equiv \dot{k} / k$ represents the growth rate along the BGE. It is seen that the growth effect depends not only on the sign of $d \hat{l} / d \tau_{c}$, but also on the sign of $a \beta-\gamma(b / \eta)\left\{1+(1-\hat{l})(1-\beta) \hat{l}^{-1}\right\}$. In particular, since the sign of $a \beta-\gamma(b / \eta)\left\{1+(1-\hat{l})(1-\beta) \hat{l}^{-1}\right\}$ may be negative or positive, the one-to-one 
relationship between the stability properties and the growth effects breaks down as long as social status concern (i.e., $\gamma \neq 0$ ) is present. Taken together, we can summarize the results as follows.

Proposition 2 An increase in the consumption tax raises the BGE level of employment and the balanced growth rate if the BGE is locally indeterminate. When the BGE is locally determinate, its increase lowers the BGE level of employment, but raises (reduces) the balanced growth rate if and only if a $\beta-$ $\gamma(b / \eta)\left\{1+(1-\hat{l})(1-\beta) \hat{l}^{-1}\right\}<0(>0)$.

Consider the intuition underlying Proposition 2. An increase in consumption makes consumption expensive relative to leisure, which in turn causes a fall in the consumption-capital ratio, given a capital stock. Due to the fall in the ratio $c / k$, the $\dot{k} /\left.k\right|_{l=\hat{\imath}}$ curve immediately shifts upward, while the $\dot{c} /\left.c\right|_{l=\hat{l}}$ curve remains unchanged, as illustrated in Figs.1-3.

Consider first the case where $N^{\prime}(\hat{l})<0$, as depicted in Fig.1. The new BGE represented by point $E_{1}$ will be located to the northeast of the original intersection point $E_{0}$. Thus, the increase in the consumption tax gives rise to $\dot{k} / k>\dot{c} / c$ at the level of employment associated with the initial intersection point $E_{0}$, and, hence, the ratio $c / k$ is declining. Although both the labor demand and labor supply curves continue to shift upward in the labor market through time as a result of the continuing increases in $k$ and $c$, it follows from (11) that employment should rise in response to the decreased ratio $c / k$. Since the higher $l$ is compatible with the new BGE featuring higher employment, the level of employment is gradually increasing to the new BGE level. As a consequence, the BGE displays indeterminacy, which involves a higher longrun level of employment and a higher balanced growth rate.

Next, consider the case where $N^{\prime}(\hat{l})>0$, as depicted in Figs.2 and 3. The new BGE at point $E_{1}$ will be located at the southwest (northwest) of the initial intersection point $E_{0}$ in Fig.2 (Fig.3) subsequent to the rise in the consumption tax. Since $\dot{k} / k>\dot{c} / c$ at point $E_{0}$ in Figs. 2 and 3 , the ratio $c / k$ is declining, which leads to higher employment. However, the higher level of employment is not compatible with the new BGE at point $E_{0}$ featuring 
the lower level of employment in both cases. Hence, employment should immediately jump to the new BGE level at point $E_{1}$. Hence, the BGE turns out to be determinate and the level of employment always falls. Nevertheless, the growth rate may end up rising or falling depending on whether the $\dot{c} /\left.c\right|_{l=\hat{l}}$ curve is negatively or positively sloped, as shown in Fig.2 and Fig.3.

Chang (2006) finds that an increase in the consumption tax always raises the long-term growth rate of the endogenous growth model with wealthenhanced status preferences. This finding runs in sharp contrast with our results in which a rise in consumption taxation may or may not stimulate long-run growth, depending on whether the balanced growth path (BGP) is determinate or indeterminate and/or on the magnitude of social status concern (i.e., the size of $\gamma$ ). In addition, although he shows that when social status concern is absent, the neutrality of consumption taxation in the growth rate sense recovers, this feature does not emerge in our model with $\gamma=0$. These differences clearly stem from the fact that he assumes inelastic labor supply, whereas we assume endogenous labor supply. More importantly, the assumption of elastic labor supply makes indeterminacy of equilibria possible, which would provide an additional channel through which the consumption tax affects a growth rate. More precisely, in a determinate BGE of our model, the supply of labor is decreased, which reduces the return to capital, $a l^{\beta}$, but intensifies the desire for social status. Accordingly, these two effects on savings and thus on the growth rate work in opposite directions. In an indeterminate BGE, the supply of labor is increased but the desire for social status is discouraged, so that these two effects on the effective rate of return on capital work in opposite directions. In contrast, in Chang's model, the only wealth-enhanced social status effect operates because of the absence of leisure-labor choice; consequently, the effective rate of return on capital is unambiguously enhanced, which boosts savings and thus the economy's growth rate. ${ }^{7}$

\footnotetext{
${ }^{7}$ Chang (2006) has also conducted the same analysis using an exogenous growth model and has found that an increase in the consumption tax not only raises the steady state level of capital stock, but also improves steady state welfare in the presence of wealthenhanced social status. In contrast, we have found that these effects are qualitatively ambiguous in an exogenous growth version of the relative wealth model in Section 4 (details
} 
Finally, we examine the welfare effects along the BGE in response to an increase in the consumption tax. ${ }^{8}$ The society's welfare (i.e., the intertemporal utility of the representative agent) along the BGE path, denoted by $W_{B G}^{1}$, is obtained by substituting (11) into $c$ into (6) and manipulating:

$$
W_{B G}^{1} \equiv \frac{1}{1-\sigma}\left[\frac{\left\{c_{0}(1-\hat{l})^{\eta} k_{0}^{(1-\theta) \gamma}\right\}^{1-\sigma}}{\rho-\{1+(1-\theta) \gamma\}(1-\sigma) \hat{g}}-\frac{1}{\rho}\right],
$$

where $c_{0}\left[=b k_{0} \hat{l}^{\beta-1}(1-\hat{l}) / \eta\left(1+\tau_{c}\right)\right]$ is the endogenously determined initial level of consumption situated in the BGE path. Differentiating the righthand side of (21) with respect to the consumption tax rate results in:

$$
\frac{d W_{B G}^{1}}{d \tau_{c}}=\frac{-\left\{c_{0}(1-\hat{l})^{\eta} k_{0}^{(1-\theta) \gamma}\right\}^{(1-\sigma)} \hat{l}^{\beta-1}}{N^{\prime}(\hat{l})\left(1+\tau_{c}\right)[\rho-\{1+(1-\theta) \gamma\}(1-\sigma) \hat{g}]^{2}} \Gamma(\hat{l})
$$

where

$$
\begin{gathered}
\Gamma(\hat{l}) \equiv\left[\left(\beta-\frac{b}{1+\tau_{c}}\right)\{\sigma-(1-\sigma) \gamma(1-\theta)\}\{\rho-\{1+\gamma(1-\theta)\}(1-\sigma) \hat{g}\}\right. \\
\left.+b\left\{\hat{l}+\frac{\gamma}{\eta}(1-\hat{l})\left(\frac{1-\theta}{1+\tau_{c}}-1\right)\right\}\{a \beta-\gamma \Lambda(\hat{l})\} \hat{l}^{\beta-1}\right] .
\end{gathered}
$$

When $\gamma=0$, it is seen that the sign of (22) depends only on the sign of $N^{\prime}(\hat{l})$. As a result, $d W_{B G}^{1} / d \tau_{c}>0(<0)$ if and only if the BGP is indeterminate (determinate). However, when $\gamma \neq 0$, the welfare effect of consumption taxation is ambiguous because of the ambiguous sign of the term $a \beta-\gamma \Lambda(\hat{l})$

of the derivation are available upon request to the corresponding author). In Chang's model, the consumption tax distorts the MRS between consumption and wealth (capital holdings), because the increase in the consumption tax makes the cost of purchasing consumption goods relative to capital goods more expensive, which in turn stimulates the demand for capital, because the effective rate of return on capital is increased. By contrast, in our exogenous growth model, there is an additional distortion in the MRS between consumption and leisure, which reduces labor supply and thus the rate of return on capital. Because of these conflicting effects, the steady state capital stock may or may not rise.

${ }^{8}$ When the BGE is indeterminate, the economy follows a transitional path from the initial BGE to the new BGE subsequent to changes in the consumption tax. In order to evaluate the welfare effects more accurately, we need to access the welfare changes that take place during a transition path as well. However, for comparison purposes and analytical tractability, we postulate that the economy is initially in the new BGE. 
in $\Gamma(\hat{l})$. Hence, we summarize as follows.

Proposition 3 The effect of the consumption tax on social welfare along the $B G E$ path is qualitatively ambiguous. When the desire for wealth-enhanced social status is absent, the welfare effect of the consumption tax is positive (negative) if and only if the BGE is locally indeterminate (determinate).

This ambiguous result can be explained as follows. Consider the case of a determinate BGE. The reduction in employment subsequent to an increase in the consumption tax lowers the return to capital, $k l^{\beta-1}$, while strengthening the desire for wealth-enhanced social status, so that the net effects on the effective rate of the return on capital and thus the growth rate of consumption are uncertain (when $\gamma \neq 0$ ). In addition, there is another source that affects social welfare as a result of substituting consumption to leisure in response to the increased consumption tax. Hence, these impacts together on social welfare are ambiguous.

In contrast, it follows from (22) that when there is no social status concern (i.e., $\gamma=0$ ), an increase in the consumption tax unambiguously boosts (reduces) the growth rate in an indeterminate (determinate) BGE. Since the positive effect on consumption growth overweighs the negative effect of increased labor supply, the tax increase unambiguously enhances (reduces) social welfare in an indeterminate (determinate) BGE. In short, the growth impact on consumption plays a dominant role in determining the welfare effect when $\gamma=0$. However, if $\gamma \neq 0$, the increased labor supply also discourages the desire for social status, which in turn has a negative impact on consumption growth, thereby making the welfare effect of the consumption tax ambiguous.

\section{Households care about own and others' con- sumption}

In this section we consider the case where household $i$ 's instantaneous utility depends on its own consumption as well as on others' consumption levels. 
Except for this preference structure, we retain the same structure of the model as in the previous section. Hence, the intertemporal utility function of household $i$ is given by the following functional form:

$$
\int_{0}^{\infty} U\left(c_{i}, l_{i}, c\right) e^{-\rho t} d t \equiv \int_{0}^{\infty} \frac{\left[c_{i}\left(1-l_{i}\right)^{\eta} c^{\gamma}\right]^{1-\sigma}-1}{1-\sigma} e^{-\rho t} d t
$$

where $c$ represents the average level of consumption for all households, which is taken as given for each household. The parameter $\gamma$ measures the degree of social status concern for other people's consumption levels. ${ }^{9}$

The instantaneous utility in (23) encompasses the relative consumption model when $\gamma=-1$, and the standard Ramsey model in which individuals care about their own consumption only when $\gamma=0$ as special cases. Moreover, since consumption externalities may be positive or negative, we allow for positive or negative values for $\gamma$. When $\gamma<0$, individuals turn out to be jealous, in a way that society's average consumption reduces the individual's utility for a given level of own consumption. Nevertheless, since others' consumption increases the marginal utility of own consumption, individual preferences exhibit the 'keeping up with the Joneses' feature discussed in Gali (1994). When $\gamma>0$, individuals turn out to be altruistic such that utility is increasing with average consumption. Here, others' consumption makes an additional unit of own consumption more valuable. Following the existing literature, we assume $\gamma \in[-1,1]$ in what follows.

The first-order conditions are given by:

$$
\begin{gathered}
\frac{\left[c_{i}\left(1-l_{i}\right)^{\eta} c^{\gamma}\right]^{1-\sigma}}{c_{i}}=\left(1+\tau_{c}\right) \lambda_{i} \\
\frac{\eta}{1-l_{i}}\left[c_{i}\left(1-l_{i}\right)^{\eta} c^{\gamma}\right]^{1-\sigma}=\lambda_{i} w \\
\frac{\dot{\lambda}_{i}}{\lambda_{i}}=\rho+\delta-r
\end{gathered}
$$

\footnotetext{
${ }^{9}$ We drop the parameter $\theta$ from the instantaneous utility function in (23) for notional convenience, unlike that in (6). As a result, the parameter $\gamma$ here has a dual role in measuring the strength of consumption externalities from others' consumption and the weight on the utility toward social status.
} 
together with the initial and transversality conditions. ${ }^{10}$

Dividing (25) by (24) results in the same MRS condition as (11). Note, however, that although the Euler equation (26) differs from (10), it is the same as the Euler equation of the standard Ramsey growth model without social status concern. In other words, the presence of consumption externalities does not form an engine of growth, unlike the desire for wealth-enhanced social status in the previous model.

Imposing symmetry, taking the time derivative of the logarithm of (24) and combining with (26) yields:

$$
[-\sigma+(1-\sigma) \gamma] \frac{\dot{c}}{c}-(1-\sigma) \eta \frac{i}{1-l}=\rho-a l^{\beta}+\delta .
$$

Substituting (13) into $\dot{c} / c_{l=\hat{l}}$ into (27), together with the goods market equilibrium condition (14), and rearranging, we obtain:

$$
\bar{l}=\frac{M(l)}{\Omega(l)},
$$

where

$$
M(l) \equiv \rho-\left(a l^{\beta}-\delta\right)+[\sigma-(1-\sigma) \gamma]\left[l^{\beta}-\frac{b}{\eta} \frac{1-l}{1+\tau_{c}} l^{\beta-1}-\delta\right],
$$

and

$$
\Omega(l) \equiv[\sigma-(1-\sigma)(\eta+\gamma)] \frac{l}{1-l}+[\sigma-(1-\sigma) \gamma](1-\beta) .
$$

Although $\sigma-(1-\sigma) \eta>0$ is implied by the concavity of the utility function and $\sigma-(1-\sigma) \gamma>0$ is implied by the assumption of positive growth [see (31)], the sign of $\Omega(l)$ is still ambiguous.

In order to interpret the ambiguous sign of $\Omega(l)$, we utilize the concept

\footnotetext{
${ }^{10}$ The transversality condition associated with the BGE, $\lim _{t \rightarrow \infty} k_{i} \lambda_{i} e^{-\rho t}=0$, is satisfied if $\rho>\hat{g}(1+\gamma)(1-\sigma)$, where $c_{i 0}$ is the initial level of household $i$ 's consumption, which should satisfy (11), given $k_{i}$ and $\hat{l}_{i}$.
} 
of the Frisch labor supply curve given by: ${ }^{11}$

$$
\log w=\text { const }-\frac{\log \lambda}{\sigma-(1-\sigma) \gamma}+\left[\frac{(1-\sigma) \eta}{\sigma-(1-\sigma) \gamma}-1\right] \log (1-l)
$$

which is obtained from substituting (11) into $c$ in (24) and taking logs of the resultant expression, where the expression 'const' in (29) represents constants. Differentiating (29) with respect to $l$ gives the slope of the Frisch labor supply curve:

$$
-\left[\frac{(1-\sigma) \eta}{\sigma-(1-\sigma) \gamma}-1\right] \frac{1}{1-l} .
$$

When $\sigma \geq 1$, it follows from the assumption $\sigma-(1-\sigma) \gamma>0$ [see (31)] that the sign of (30) is positive (i.e., the Frisch labor supply curve has the usual positive slope), and thus $\Omega(l)>0$. When $\sigma<1$, the sign of (30) may be negative, and thus the Frisch labor supply curve may be negatively sloped without violating the concavity of the utility function. ${ }^{12}$

Further, if this curve is steeper than the labor demand curve (whose slope is equal to $(\beta-1) / l<0)$; that is, if:

$$
-\left[\frac{(1-\sigma) \eta}{\sigma-(1-\sigma) \gamma}-1\right] \frac{1}{1-l}<\frac{\beta-1}{l}<0,
$$

then $\Omega(l)<0$. In this case, the Frisch labor supply curve crosses the labor demand curve with the 'wrong' slopes, depicted in Fig.4.

The BGE condition is obtained by setting $M(\hat{l})=0$; that is:

$$
\frac{a \hat{l}^{\beta}-(\rho+\delta)}{\sigma-(1-\sigma) \gamma}=\hat{l}^{\beta}-\frac{b}{\eta} \frac{(1-\hat{l}) \hat{l}^{\beta-1}}{1+\tau_{c}}-\delta .
$$

\footnotetext{
${ }^{11}$ According to Bennett and Farmer (2000), the Frisch labor supply curve is where labor supply is a function of the real wage holding the marginal utility of consumption (i.e., $\lambda$ ) constant.

${ }^{12}$ As correctly pointed out by Hintermaier (2003), the 'wrong' slope of the Frisch labor supply curve is not consistent with the concavity of the nonseparable utility function posited by Bennett and Farmer (2000). In light of this fact, we can say that the presence of a household's status concern makes it possible for the Frisch labor supply curve to cross the labor demand curve with the 'wrong' slopes without violating the concavity of the utility function.
} 


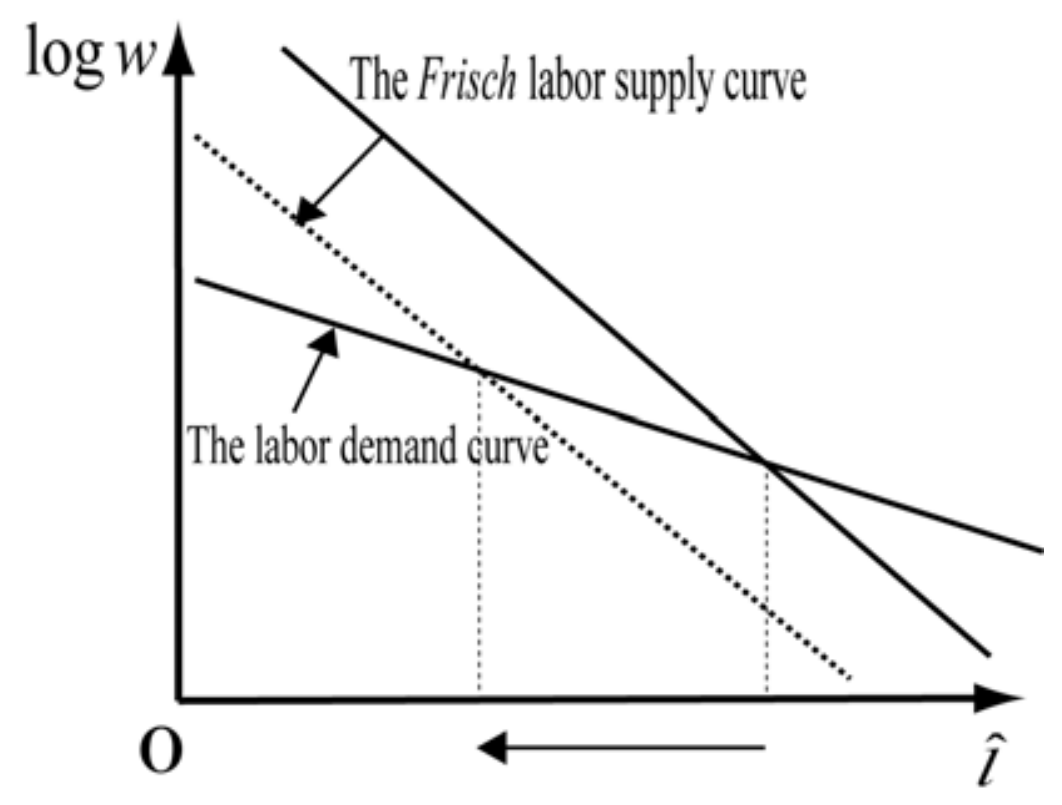

Figure 4: The labor demand and Frisch labor supply curves cross with 'wrong' slopes (i.e., $\Omega(\hat{l})<0)$.

We assume that $\sigma-(1-\sigma) \gamma>0$ in order to ensure that the BGE path displays positive growth.

Applying a procedure analogous to that in the previous section, we obtain:

$$
\left.\frac{d(\dot{l} / l)}{d l}\right|_{l=\hat{l}}=\frac{M^{\prime}(\hat{l}) \Omega(\hat{l})-M(\hat{l}) \Omega^{\prime}(\hat{l})}{\{\Omega(\hat{l})\}^{2}}=\frac{M^{\prime}(\hat{l})}{\Omega(\hat{l})}
$$

where $M^{\prime}(\hat{l})=0$ and:

$M^{\prime}(\hat{l}) \equiv[\sigma-(1-\sigma) \gamma]\left[-\frac{a \beta \hat{l}^{\beta-1}}{\sigma-(1-\sigma) \gamma}+\beta \hat{l}^{\beta-1}+\frac{b}{\eta} \frac{\left\{1+(1-\hat{l})(1-\beta) \hat{l}^{-1}\right\} \hat{l}^{\beta-1}}{1+\tau_{c}}\right]$

Taken together, we have the following proposition.

Proposition 4 Assume that the utility function is given by (23). Then, the $B G E$ is locally indeterminate (determinate) if and only if $M^{\prime}(\hat{l})<0$ $\left(M^{\prime}(\hat{l})>0\right)$, provided the labor demand and Frisch labor supply curves cross 
with the 'normal' slopes (i.e., $\Omega(\hat{l})>0)$, where:

$$
\operatorname{sign}\left[M^{\prime}(\hat{l})\right]=\operatorname{sign}\left[-a \beta+\{\sigma-(1-\sigma) \gamma\}\left\{\beta+\frac{\Lambda(\hat{l})}{1+\tau_{c}}\right\}\right] \text {, }
$$

$\Omega(\hat{l}) \equiv[\sigma-(1-\sigma)(\eta+\gamma)][\hat{l} /(1-\hat{l})]+[\sigma-(1-\sigma) \gamma](1-\beta)$, and $\Lambda(\hat{l}) \equiv$ $(b / \eta)\left\{1+(1-\hat{l})(1-\beta) \hat{l}^{-1}\right\}>0$. The opposite results hold if the labor demand and Frisch labor supply curves cross with the 'wrong' slopes (i.e., $\Omega(\hat{l})<0)$.

It is important to note that there are two sources of indeterminacy; namely, the signs of $\Omega(\hat{l})$ and $M^{\prime}(\hat{l})$, unlike the model of wealth-enhanced social status in the previous section. When $\Omega(\hat{l})>0$, we obtain the relationship between the stability properties of the model and the relative slope of the $\dot{c} /\left.c\right|_{l=\hat{l}}$ and $\dot{k} /\left.k\right|_{l=\hat{l}}$ curves similar to that in the relative wealth model. However, if $\Omega(\hat{l})<0$, the results are reversed.

As to the consumption externalities model, in order to examine the empirical plausibility of indeterminacy, we first assume the parameter and empirical sets given in the relative wealth model (see Tables 1 and 2) except for $\sigma=$ $0.66, \gamma=0.95$ and $l=0.31$. Using these calibrated values, we obtain the vector of other parameters $\{\beta, z / y, a, b, \eta, \rho\}=\{0.73,0.06,0.471,0.529,1.79,0.076\}$, which is consistent with the empirical facts; consequently, we obtain $M^{\prime}(\hat{l})=$ $0.065>0$ and $\Omega(\hat{l})=-0.031<0$. This implies that indeterminacy arises when the Frisch labor supply curve crosses the labor demand curve with the 'wrong' slopes.

On the other hand, we can also detect a case where indeterminacy occurs even when the Frisch labor supply and labor demand curves cross with the 'normal' slopes. To show this, we assume $\sigma=0.66, \gamma=0.95$, $g=0.025, c / y=0.69, l=0.4$, while the rest of the parameter values are the same as those in Tables 1 and 2. With these values, we get the vector $\{\beta, z / y, a, b, \eta, \rho\}=\{0.99,0.07,0.496,0.504,1,0.092\}$, which gives rise to $M^{\prime}(\hat{l})=-0.0006<0$ and $\Omega(\hat{l})=0.0019>0$.

Moreover, we can easily find many other combinations of empirically plausible parameter values that are consistent with the emergence of indetermi- 
nacy. Note also that higher values of $\gamma$ are consistent with the emergence of indeterminacy compared to the relative wealth model. These results indicate that under empirically plausible parameter values it is more likely for the consumption externalities model to generate indeterminacy as compared to the relative wealth model.

\section{The effects of consumption taxation in the consumption externalities model}

This section examines the growth effects of consumption taxation. As in Section 4, totally differentiating (31) and rearranging yields:

$$
\frac{d \hat{l}}{d \tau_{c}}=-[\sigma-(1-\sigma) \gamma] \frac{b}{\eta} \frac{(1-\hat{l}) \hat{l}^{\beta-1}}{\left(1+\tau_{c}\right)^{2}}\left[M^{\prime}(\hat{l})\right]^{-1}
$$

In a manner analogous to the previous section, we can get:

$$
\frac{d \hat{g}}{d \tau_{c}}=\frac{a \beta \hat{l}^{\beta-1}}{\sigma-(1-\sigma) \gamma} \frac{d \hat{l}}{d \tau_{c}}
$$

Taken together, it is seen that whether the BGE growth rate may rise or fall with the consumption tax hinges solely on the sign of $M^{\prime}(l)$. Note also that unlike the previous model, employment and the growth rate along the BGE path move in the same direction in response to changes in the consumption tax.

Proposition 5 An increase in the consumption tax raises (reduces) the BGE level of employment as well as the balanced growth rate if and only if the $B G E$ is locally indeterminate (determinate), provided the Frisch labor supply curve crosses the labor demand curve with the 'normal' slopes, and vice versa otherwise.

We take a closer look at Proposition 5. An increase in the consumption tax shifts the $\dot{k} /\left.k\right|_{l=\hat{l}}$ curve downward, keeping $\dot{c} /\left.c\right|_{l=\hat{l}}$ curve unchanged as 
before. It is important to note that the $\dot{c} /\left.c\right|_{l=\hat{l}}$ curve always takes a positive slope, unlike in the previous model.

First, we consider the case where $M^{\prime}(\hat{l})<0$, as shown in Fig.1. An increase in the consumption tax leads to $\dot{k} / k>\dot{c} / c$ at the initial employment level associated with point $E_{0}$, and then the ratio $c / k$ declines. As a result, this shifts the Frisch labor supply curve leftward. When $\Omega(\hat{l})<0$, this shift gives rise to a fall in the level of employment, depicted in Fig.4. However, since the new $B G E$ at point $E_{1}$ is located to the northeast of the initial BGE at point $E_{0}$, the new BGE entails higher employment. As a result, the new BGE turns out to be unstable (i.e., locally determinate) and displaying a higher growth rate. On the other hand, when $\Omega(\hat{l})>0$, an increase in the consumption tax causes the Frisch labor supply curve to shift rightward, which in turn produces higher employment. Hence, the new BGE entails higher employment and local indeterminacy.

Next, we study the case of $M^{\prime}(\hat{l})>0$ in Fig.2. The new BGE at point $E_{1}$ will be located to the southwest of the original intersection point $E_{0}$ subsequent to an increase in the consumption tax. As a result, the long-run growth rate falls. We can also show that the dynamic properties of the model will be reversed; that is, when $\Omega^{\prime}(\hat{l})>0\left(\Omega^{\prime}(\hat{l})<0\right)$, the new BGE featuring a lower growth rate is locally determinate (indeterminate). Nevertheless, the effect of the consumption tax on long-run growth depends only on the relative slope of the $\dot{k} / k$ and the $\dot{c} / c$ curves (i.e., the sign of $M^{\prime}(\hat{l})$ ); namely, the relative size of the elasticities of the demand and supply curves of capital in response to changes in the level of employment.

As in the previous section, we examine the welfare effects of changes in the consumption tax along the BGE path. The social welfare along the BGE path, denoted by $W_{B G}^{2}$, is obtained by substituting (11) into $c$ into (23) and manipulating:

$$
W_{B G}^{2} \equiv \frac{1}{1-\sigma}\left[\frac{\left\{c_{0}^{1+\gamma}(1-\hat{l})^{\eta}\right\}^{1-\sigma}}{\rho-(1+\gamma)(1-\sigma) \hat{g}}-\frac{1}{\rho}\right],
$$

where $c_{0}\left[=k_{0} b \hat{l}^{\beta-1}(1-\hat{l}) / \eta\left(1+\tau_{c}\right)\right]$ is the endogenously determined initial level of consumption situated on the BGE path. Appendix B demonstrates 
that $d W_{B G}^{1} / d \tau_{c} \mathbf{R} 0$ if and only if $M^{\prime}(\hat{l}) \mathbf{S} 0$ when $\gamma \geq 0$, while its sign is uncertain when $\gamma<0$. To sum up, we have the following proposition.

Proposition 6 Assume that individuals are altruistic (i.e., $\gamma>0$ ) or consumption externalities are absent (i.e., $\gamma=0$ ). An increase in the consumption tax raises (lowers) welfare along the BGE path if and only if the $B G E$ is locally indeterminate (determinate), provided the Frisch labor supply curve crosses the labor demand curve with the 'normal' slopes. The results are reversed provided the Frisch labor supply curve crosses the labor demand curve with the 'wrong' slopes. However, if individuals are jealous of others' consumption (i.e., $\gamma<0$ ), the welfare effect of consumption tax is uncertain.

Proposition 6 can be interpreted as follows. The consumption growth effect plays a dominant role in determining the welfare effect of the consumption tax, as in the previous model. This can be highlighted by setting $\gamma=0$ in (B.7) of Appendix B. In this case, the wealth effects of consumption taxation depend solely on the growth effects of consumption taxation in (35). As long as $\gamma \geq 0$, the consumption growth effect is further enhanced so that it has an unambiguous impact on welfare. In contrast, when $\gamma<0$ (i.e., jealous), the growth of other people's consumption reduces the utility of their own consumption, thereby depressing the consumption growth effect. This makes the sign of the welfare effect ambiguous when $\gamma<0 .{ }^{13}$

\footnotetext{
${ }^{13}$ However, we find that there is no tied relationship between the effects of consumption taxation and the stability properties of the steady state equilibrium in an exogenous growth version of the consumption externalities model presented in Section 6, unlike in the corresponding endogenous growth model. Since in this case we have assumed that $\alpha<1$, the steady state is characterized by the equations $k^{\alpha-1} l^{\beta}-(c / k)-\delta=0$ and $\rho+\delta-a k^{\alpha-1} l^{\beta}=0$. These two conditions can be combined to yield:

$$
\rho+\delta=a k^{\alpha-1} l^{\beta}=a\left(\frac{c}{k}+\delta\right) .
$$
}

Substituting this expression into $c$ in the $M R S$ condition:

$$
\frac{\eta}{1-l} c=\frac{b k^{\alpha} l^{\beta-1}}{1+\tau_{c}}
$$

and rearranging results in $l=(\rho+\delta) /\left[(\eta / b)\{\rho+(1-a) \delta\}\left(1+\tau_{c}\right)+\rho+\delta\right]$. By taking logs and differentiating the above expression with respect to $\tau_{c}$ yields: 


\section{Concluding remarks}

This paper has examined the relationship between consumption taxation and long-term growth, when individuals care about others' wealth or others' consumption. The most novel contribution of this paper is to clarify how the inclusion of endogenous labor supply influences the implications of a consumption tax policy for economic growth in such models. In Chang's (2006) model with the desire for wealth-enhanced social status and with fixed labor supply, he focuses only on distortions in the $M R S$ between own consumption and relative wealth, whereas in our model there is an additional distortion associated with the $M R S$ between own consumption and leisure that is also created by the consumption tax. This extension serves to precisely assess efficiency losses or welfare losses associated with consumption taxation in more realistic economies. In addition, the introduction of endogenous labor supply would profoundly affect the effects of consumption taxation through alternations in the nature of the dynamic equilibrium, whereby indeterminacy of equilibria may be possible. This distinguishing feature would potentially make the impacts of consumption taxation opposite to the results of Chang in which higher rates of consumption tax always stimulate economic growth.

The second message is that the consumption externalities model presented in this paper has, in general, a relatively stronger tendency to generate indeterminacy than the wealth-enhanced social status model does. One of the reasons is that the consumption externalities model allows multiple sources

$$
\frac{1}{l} \frac{d l}{d \tau_{c}}<0
$$

Further, taking logs of $\rho+\delta=a k^{\alpha-1} l^{\beta}$ and differentiating gives:

$$
\frac{1}{k} \frac{d k}{d \tau_{c}}=\frac{\beta}{1-\alpha} \frac{1}{l} \frac{d l}{d \tau_{c}}<0
$$

Taking into account the constancy of the ratio $c / k$ in the steady state, we have:

$$
\frac{1}{c} \frac{d c}{d \tau_{c}}=\frac{1}{k} \frac{d k}{d \tau_{c}}<0
$$

Using these results, it is straightforward to show that the effect on steady state welfare is negative. These adverse effects are caused mainly by the reduction in labor supply. 
to generate indeterminacy; namely, the relative elasticity of the capital demand and supply curves as well as the relative elasticity of the labor demand and supply curves, although both the relative wealth and consumption externalities models suffer from inefficiency stemming from externalities in the demand side of the economy. This result indicates that the likelihood of indeterminacy and the implications of consumption tax policy hinge critically on which sources on the demand side of the economy create such externalities.

There are extensions in several directions. First, although further insights could be gained by introducing other factor income taxes such as capital income and labor income taxes, from the viewpoint of tax reforms in practice it would be a more important and interesting question to ask whether a tax reform such as replacing an income tax or a labor income tax with a consumption tax may or may not encourage capital accumulation, and thus improve social welfare. In light of the results of this paper it is likely that such a replacement tends to give rise to growth- (welfare-) enhancing effects when the economy exhibits indeterminacy. Second, and more interestingly, we may introduce heterogenous households in terms of initial wealth holdings and preferences parameters such as the strength of the desire for social status or the elasticity of labor supply along the lines of Futagami and Shibata (1998), and Long and Shimomura (2004). Such a heterogenous setting would provide richer implications of a consumption tax policy as a consequence of distributional effects in addition to the growth effects activated by the distortions in consumption-leisure and/or consumption-wealth choices. Despite its analytical difficulty, this extension surely deserves further study.

\section{Appendix A: Slopes of the $\dot{c} /\left.c\right|_{l=\hat{l}}$ and $\dot{k} /\left.k\right|_{l=\hat{l}}$ curves in the relative wealth model}

Along a BGE labor supply is a constant, i.e., $i=0$. Then we consider the optimal rate of growth of consumption when $i=0$ in (12) becomes:

$$
-\sigma \frac{\dot{c}}{c}+(1-\sigma) \gamma(1-\theta) \frac{\dot{k}}{k}=\rho+\delta-\left[a l^{\beta}+\gamma\left(1+\tau_{c}\right) \frac{c}{k}\right] .
$$


Along the BGE path, the following condition holds:

$$
\frac{\dot{c}}{c}=\frac{\dot{k}}{k}
$$

Substituting (A.2) into $\dot{k} / k$ in (A.1), together with (11), and rearranging, we obtain:

$$
\left.\frac{\dot{c}}{c}\right|_{l=\hat{l}}=\frac{a \hat{l}^{\beta}-\delta-\left\{\rho-\gamma(b / \eta)(1-\hat{l}) \hat{l}^{\beta-1}\right\}}{\sigma-(1-\sigma) \gamma(1-\theta)} .
$$

We differentiate the right-hand side of (A.3) with respect to $\hat{l}$ to give:

$$
\left.\frac{d(\dot{c} / c)}{d l}\right|_{l=\hat{l}}=\frac{\beta a \hat{l}^{\beta-1}-\gamma(b / \eta)\left\{1+(1-\hat{l})(1-\beta) \hat{l}^{-1}\right\} \hat{l}^{\beta-1}}{\sigma-(1-\sigma) \gamma(1-\theta)}
$$

which implies that the $\dot{c} /\left.c\right|_{l=\hat{l}}$ curve is positively (negatively) sloped if and only if $a \beta-\gamma(b / \eta)\left\{1+(1-\hat{l})(1-\beta) \hat{l}^{-1}\right\}>0(<0)$.

As to the $\dot{k} /\left.k\right|_{l=\hat{l}}$ curve, substituting (11) into (14), we differentiate the resulting expression with respect to $\hat{l}$ to obtain:

$$
\left.\frac{d(\dot{k} / k)}{d l}\right|_{l=\hat{\imath}}=\beta \hat{l}^{\beta-1}+\frac{b}{\eta} \frac{\hat{l}^{\beta-1}\left\{1+(1-\hat{l})(1-\beta) \hat{l}^{-1}\right\}}{1+\tau_{c}}>0 .
$$

This implies that the $\dot{k} /\left.k\right|_{l=\hat{l}}$ curve is positively sloped as well.

Moreover, by comparing (A.4) and (A.5) with the right-hand side of (18) it turns out that the first term and the terms within the braces in the second brackets on the right-hand side of (18) correspond to the slopes of the $\dot{c} /\left.c\right|_{l=\hat{l}}$ curve and the $\dot{k} /\left.k\right|_{l=\hat{l}}$, respectively. Hence, it is seen that when $N^{\prime}(\hat{l})<0$, the $\dot{c} /\left.\right|_{l=\hat{l}}$ curve has a steeper upward slope than the $\dot{k} /\left.k\right|_{l=\hat{l}}$ curve, and vice versa. 


\section{Appendix B: Welfare effect}

Differentiating with respect to $\tau_{c}$ yields:

$$
\frac{d W_{B G}^{2}}{d \tau_{c}}=\left\{c_{0}(1-\hat{l})^{\eta}\right\}^{1-\sigma} \frac{(1+\gamma) D}{[\rho-(1+\gamma)(1-\sigma) \hat{g}]^{2}},
$$

where

$$
D \equiv\left[\frac{1}{c_{0}} \frac{d c_{0}}{d \tau_{c}}-\frac{\eta}{1-\hat{l}} \frac{1}{1+\gamma} \frac{d \hat{l}}{d \tau_{c}}\right][\rho-(1+\gamma)(1-\sigma) \hat{g}]+\frac{d \hat{g}}{d \tau_{c}}
$$

Differentiating $c_{0}$ in (11) with respect to $\tau_{c}$ gives:

$$
\frac{d c_{0}}{d \tau_{c}}=\frac{c_{0}}{\hat{l}(1-\hat{l})}[(1-\hat{l}) \beta-1] \frac{d \hat{l}}{d \tau_{c}}-\frac{c_{0}}{1+\tau_{c}} .
$$

Substituting (B.2), (34) and (35) into the expression D in (B1) and rearranging results in:

$$
\begin{gathered}
D \equiv \frac{-1}{M^{\prime}(\hat{l})\left(1+\tau_{c}\right)}\left[\left\{\frac{1}{\hat{l}(1-\hat{l})}\left[(1-\hat{l}) \beta-1-\frac{\eta \hat{l}}{1+\gamma}\right]\{\sigma-(1-\sigma) \gamma\}\right.\right. \\
\left.\left.\times \frac{b}{\eta} \frac{(1-\hat{l}) \hat{l}^{\beta-1}}{1+\tau_{c}}+M^{\prime}(\hat{l})\right\}\{\rho-(1+\gamma)(1-\sigma) \hat{g}\}+a \beta \hat{l}^{\beta-1} \frac{b}{\eta} \frac{(1-\hat{l}) \hat{l}^{\beta-1}}{1+\tau_{c}}\right] .
\end{gathered}
$$

Ignoring the terms $-1 /\left[M^{\prime}(\hat{l})\left(1+\tau_{c}\right)\right]$ and $\hat{l}^{\beta-1}$ in (B.3), and using the definition of $M^{\prime}(\hat{l})$, we have:

$$
\begin{aligned}
& {\left[\frac{1}{\hat{l}(1-\hat{l})}\left\{(1-\hat{l}) \beta-1-\frac{\eta \hat{l}}{1+\gamma}\right\}\{\sigma-(1-\sigma) \gamma\} \frac{b}{\eta} \frac{1-\hat{l}}{1+\tau_{c}}\right.} \\
& \left.+\{\sigma-(1-\sigma) \gamma\}\left\{-\frac{a \beta}{\sigma-(1-\sigma) \gamma}+\beta+\frac{b}{\eta} \frac{\left\{1+(1-\hat{l})(1-\beta) \hat{l}^{-1}\right\}}{1+\tau_{c}}\right\}\right] \\
& \times\{\rho-(1+\gamma)(1-\sigma) \hat{g}\}+a \beta \hat{l}^{\beta-1} \frac{b}{\eta} \frac{1-\hat{l}}{1+\tau_{c}} .
\end{aligned}
$$


We can rewrite the above expression as follows:

$$
\hat{D} \equiv D_{1}\{\rho-(1+\gamma)(1-\sigma) \hat{g}\}+a \beta \hat{l}^{\beta-1} \frac{b}{\eta} \frac{1-\hat{l}}{1+\tau_{c}}
$$

where

$$
\begin{aligned}
& D_{1} \equiv \frac{1}{\hat{l}(1-\hat{l})}\left\{(1-\hat{l}) \beta-1-\frac{\eta \hat{l}}{1+\gamma}\right\}\{\sigma-(1-\sigma) \gamma\} \frac{b}{\eta} \frac{1-\hat{l}}{1+\tau_{c}} \\
& +\{\sigma-(1-\sigma) \gamma\}\left\{-\frac{a \beta}{\sigma-(1-\sigma) \gamma}+\beta+\frac{b}{\eta} \frac{\left\{1+(1-\hat{l})(1-\beta) \hat{l}^{-1}\right\}}{1+\tau_{c}}\right\},
\end{aligned}
$$

which, by tedious calculation, reduces to:

$$
D_{1}=\{\sigma-(1-\sigma) \gamma\}\left\{\beta-\frac{b}{\left(1+\tau_{c}\right)(1+\gamma)}\right\}-a \beta
$$

Substituting (B.5) into (B.4) and rearranging results in:

$$
\begin{aligned}
\hat{D}= & {\left[\{\sigma-(1-\sigma) \gamma\}\left\{\beta-\frac{b}{\left(1+\tau_{c}\right)(1+\gamma)}\right\}-a \beta\right] } \\
& \times\{\rho-(1+\gamma)(1-\sigma) \hat{g}\}+a \beta \hat{l}^{\beta-1} \frac{b}{\eta} \frac{1-\hat{l}}{1+\tau_{c}} .
\end{aligned}
$$

After rewriting the BGE condition $(31)$ as $\rho-(1+\gamma)(1-\sigma) \hat{g}=(-1+a) \hat{l}^{\beta}+$ $(b / \eta)(1-\hat{l}) \hat{l}^{\beta-1}\left(1+\tau_{c}\right)^{-1}$ and substituting this expression into (B.6) and rearranging, we have:

$\hat{D}=\{\sigma-(1-\sigma) \gamma\}\left\{\beta-\frac{b}{\left(1+\tau_{c}\right)(1+\gamma)}\right\}\{\rho-(1+\gamma)(1-\sigma) \hat{g}\}+a \beta b \hat{l}^{\beta}$

which implies that $d W_{B G}^{2} / d \tau_{c} \mathrm{R} 0$ if and only if $M^{\prime}(\hat{l}) \mathrm{Q} 0$ [recalling (B.1), (B.3) and (B.4)], as long as $\gamma \geq 0$. However, it is ambiguous when $\gamma<0$. 


\section{References}

Abel, A.B., Blanchard, O.J., 1983, An intertemporal model of saving and investment, Econometrica 51, 675-692.

Auerbach, A.J., Kotlikoff, L.J., 1987, Dynamic Fiscal Policy, Cambridge University Press.

Alonso-Carrera, J., Caballè, J., Raurich, X., 2005, Can consumption spillovers be a source of equilibrium indeterminacy?, Working Papers Series 0105, RGEA, University de Vigo.

Bakshi, G., Chen, Z., 1996, The spirits of capitalism and stock-market prices, American Economic Review 86, 133-157.

Benhabib, J., and Farmer, R., 1994, Indeterminacy and increasing returns, Journal of Economic Theory 63, 19-41.

Bennett, R., Farmer, R., 2000, Indeterminacy with non-separable utility, Journal of Economic Theory 93, 118-143.

Cole, H.L., Mailath, G.J., Postlewaite, A., 1992, Social norms, saving behavior, and growth, Journal of Political Economy 100, 1092-1125..

Chang, W., 2006, Relative wealth, consumption taxation, and economic growth, Journal of Economics 88, 103-129.

Corneo, G., Jeanne, O., 1997, On relative wealth effects and the optimality of growth, Economics Letters 54, 87-92.

Duesenberry, J.S., 1949, Income, Saving and the Theory of Consumer Behavior, Cambridge.

Devereux, M.B., Love, D.R.F., 1994, The effects of factor taxation in a twosector model of endogenous growth, Canadian Journal of Economics $27,509-536$.

Fisher, W., Hof, F., 2000, Relative consumption, economic growth and taxation, Journal of Economics 72, 241-262. 
Futagami, K., Shibata, A., 1998, Keeping one step ahead of the Joneses: Status, the distribution of wealth, and long-run growth, Journal of Economic Behavior and Organization 36, 109-126.

Gali, J., 1994, Keeping up with the Joneses: Consumption externalities, portfolio choice, and asset prices, Journal of Money, Credit and Banking 26, 1-8.

Harbaugh, R., 1996, Falling behind the Joneses: Relative consumption and the growth-savings paradox, Economics Letters 53, 297-304.

Hintermaier, T., 2003, On the minimum degree of returns to scale in sunspot models of the business cycle, Journal of Economic Theory 110, 400-409.

Itaya, J., 1991, Tax incidence in a two-sector growing economy with perfect foresight, Journal of Public Economics 44, 297-304.

King, R.G., Plosser, C.I, Rebelo, S., 1988, Production, growth and business cycles: I. The basic neoclassical model, Journal of Monetary Economics $21,195-232$.

Kurz, M., 1968, Optimal economic growth and wealth effects, International Economic Review 9, 348-357.

Long, N.V., and Shimomura, K., 2004, Relative wealth, status-seeking, and catching up, Journal of Economic Behavior and Organization 53, 529542 .

Milesi-Ferretti, G.M., Roubini, N., 1998, Growth effects of income and consumption taxes, Journal of Money, Credit and Banking 30, 721-744.

Pelloni, A., Waldmann, R., 2000, Can waste improve welfare? Journal of Public Economics 77, 45-79.

Rauscher, M., 1997, Conspicuous consumption, economic growth, and taxation, Journal of Economics 66, 35-42. 
Romer, P. R., 1986, Increasing returns and long-run growth, Journal of Political Economy 94, 1002-1037.

Schenone, O.H., 1975, A Dynamic analysis of taxation, American Economic Review 65, 101-114.

Stokey, N.L., Rebelo, S., 1995, Growth effects of flat-rate taxes, Journal of Political Economy 103, 519-550.

Summers, L.H., Capital taxation and accumulation in a life cycle model, American Economic Review 71, 533-544.

Veblen, T., 1899 The Theory of the Leisure Class: An Economic Study of Institutions, New York: Modern Library.

Weber, M., 1958, The Protestant Ethic and the Spirit of Capitalism, New York: Charles Scribner's Sons.

Weder, M., 2000, Consumption externalities, production externalities and indeterminacy, Metroeconomica 51, 435-453.

Zou, H., 1994, The spirit of capitalism and long-run growth, European Journal of Political Economy 10, 279-293.

Zou, H., 1995, The spirit of capitalism and saving behavior, Journal of Economic Behavior and Organization 28, 131-143. 